\title{
Occupational therapy fieldwork educators: Examining professional quality of life
}

\author{
Emily Z. Eddy ${ }^{\mathrm{a}, \mathrm{b}, *}$, Linda Tickle-Degnen ${ }^{\mathrm{a}}$ and Mary E. Evenson ${ }^{\mathrm{b}}$ \\ ${ }^{\mathrm{a}}$ Department of Occupational Therapy, Tufts University, Medford, MA, USA \\ ${ }^{\mathrm{b}}$ Department of Occupational Therapy, MGH Institute of Health Professions, Boston, MA, USA
}

Received 21 July 2020

Accepted 20 April 2021

\begin{abstract}
.
BACKGROUND: Occupational therapy practitioners with the simultaneous working role of fieldwork educator support the growth of the profession by supervising students, but little is known about their reported burnout, compassion fatigue, and compassion satisfaction levels, and if specific work characteristics predict those levels.

OBJECTIVE: The purpose of this research was to: 1) assess the current levels of compassion fatigue, compassion satisfaction, and burnout in occupational therapy fieldwork educators through The Professional Quality of Life Scale (ProQOL), and 2) to explore how professional characteristic variables correlate and predict the measured constructs of compassion fatigue, burnout, and compassion satisfaction.

METHODS: A cross-sectional design was used, and participants were recruited from a convenience sample to complete the ProQOL and a work characteristic questionnaire.

RESULTS: On the average, 117 fieldwork educators scored higher on the subscale of compassion satisfaction when compared to those of the normed group. Linear regression analyses revealed that a higher number of roles and greater years working predicted higher compassion satisfaction.

CONCLUSIONS: This study contributes to understanding the experiences of fieldwork educators in multiple roles, their reported levels of compassion fatigue, compassion satisfaction, and burnout, and the potential for development of personal, educational and organizational resources to support professional quality of life indicators within the role of fieldwork educator.
\end{abstract}

Keywords: Practice education, working roles, compassion fatigue, burnout, compassion satisfaction

\section{Introduction}

Occupational therapy practitioners focus their work on the delivery of services to clients within their practice, however, they are often also called to fulfill many other roles, including a secondary role to educate and mentor fieldwork students, as a fieldwork, or practice, educator. Fieldwork educators support students in gaining the necessary practical, ethical, and clinical reasoning skills to become

*Address for correspondence: Emily Z. Eddy, MGH Institute of Health Professions, 36 1st Avenue, Boston, MA 02129, USA. Tel.: +1 617643 4352; E-mail: eeddy@mghihp.edu.; ORCID ID: https://orcid.org/0000-0002-2666-6009 competent at an entry-level, while serving the profession for American graduate program compliance with the Accreditation Council for Occupational Therapy Education [ACOTE®] accreditation standards for 24 weeks of full-time, supervised clinical experience [1]. Managing the multiple dimensions of client care in the service delivery context, with limited time and resources, can create the potential for exhaustion, decreased engagement at work, and decreased professional quality of life [2-4]. Adding in duties to teach, supervise, mentor, and assess a fieldwork student's competency, while simultaneously managing one's own caseload, often causes stress, role overload, role conflict and role strain, while draining personal resources and resilience [5]. The extra demands that come with fieldwork education may 
lead to burnout and compassion fatigue - two components of professional quality of life - negatively impacting the occupational therapy practitioner's satisfaction derived from the caring work of therapy and client relationships, and perceived benefits of educating students [6-8].

Experiencing compassion fatigue or burnout may decrease practitioner satisfaction with work, detracting from engagement and presence in client and student encounters [4, 9]. Furthermore, the delivery of client-centered care and student supervision may be impacted by increased turnover, absenteeism, and lower morale often associated with burnout and compassion fatigue in the health care workplace $[2,3,7]$. The trickle-down effect may contribute to decreased client outcomes and decreased client satisfaction with their health care experiences. As fieldwork educators experience emotional, physical, and mental exhaustion in meeting the demands of client caseloads and student supervision needs simultaneously, role strain and overload, and burnout may occur $[2,4,5]$. Treatment and documentation errors may rise while time and energy resources for clients and students may fall $[10,11]$, along with practitioner's perceived role competence [5].

On the other hand, working in the added role of practice educator may have satisfying outcomes. Many occupational therapy practitioners report that they enjoy teaching fieldwork students because they want to share their passion about the profession and to support the growth of a student to entry-level status; they derive personal satisfaction from supervision; and they appreciate opportunities to stay current with the latest evidence [6]. Reciprocally, students report they feel best supported when the practice (fieldwork) educator provides the "just right challenge" while encouraging autonomy and valuing the relationship [12]. By exploring the prevalence and predictors of compassion fatigue and burnout, as well as the positive aspects of work - compassion satisfaction - in therapy practitioners in educator roles, fieldwork educators may be more mindfully aware of the benefits of balance between the positive and negative facets of work duties and demands as a fieldwork educator.

\section{Challenges of the practice of occupational therapy}

One of the challenges of occupational therapy practice is to enable clients' occupational performance and participation in and through meaningful activities, while also staying emotionally present in the therapeutic relationship $[13,14]$. Client-therapist relationships in occupational therapy summon the occupational therapy practitioner to balance foundational skills, clinical reasoning, compassionate care, therapeutic use of self, and presence. The occupational therapy practitioner role also includes, but is not limited to, many job demands: meeting institutional requirements and productivity expectations; assuming other roles such as administrator, student coordinator, or rehabilitation director; cultivating the emotional, physical and psychosocial health of clients; monitoring their own stress and balance of work demands while utilizing system and personal resources [15]; collaborating with team members; and training and supervising others. Managing one's own practitioner role, along with external demands and life roles, sets up the potential for compassion fatigue and burnout $[2,3]$.

Fieldwork educators' duties include further balancing of the practitioner role alongside the educator role, to pay simultaneous attention to both client and student. Fieldwork educators concurrently manage their caseload and workload while monitoring students' goals, skill development, and professional growth. Fieldwork educators support student learning by demonstrating clinical care skills, professional work behaviors, decision-making skills, time management, and modeling therapeutic modes during intentional client interactions [16-18]. Many fieldwork educators report benefits that include the opportunities to develop supervision skills; enrich clinical reasoning; serve the profession and stay current with the literature [6]. However, Evenson et al. [6] also found that the most frequently reported challenges identified by fieldwork educators were time pressures and workload, with cost to staff time and impact on client care as also concerning. From the student's perspective, they spend much of their time observing supervisors and learning strategies of selfcare, resilience, and socialization to the profession, alongside the required client skills, evaluation processes, and documentation methods. Student success thus is also dependent on appreciating the nuances of professional and personal role balancing in the contexts of the healthcare system, home, and one's own life [18].

Fieldwork educators have the responsibility to model self-management and resilience to fieldwork students, to balance between negative and positive factors of work. Yuen [19] was the first to call upon fieldwork educators to invest more time into their 
formal training toward teaching experience with their students, and to become aware of the potential for burnout while navigating the two roles. Educators in disciplines of dentistry, nursing, occupational and speech therapies report feeling a struggle to meet the time and emotional demands of both clients' and students' needs. This is depicted as an experience of surviving instead of thriving [16, 20]. As they navigate professional and educational commitments, fieldwork educators must balance and prioritize attending to the duties of supervision and instruction of the student, while remaining available in all aspects to their clients $[5,16,17]$.

\subsection{Compassion fatigue, burnout and compassion satisfaction}

The constructs of compassion fatigue and burnout have been well-studied, and are found in the literature as different concepts, and are identified as part of the term, professional quality of life [8]. Compassion fatigue is an experience of tension and preoccupation with the suffering of those being helped, to the degree it is traumatizing to the helper [10, 21]. An occupational therapy practitioner holds on to the emotions, narratives, and problems of the client over time and outside of work. Burnout has been defined as a longer term, stress-induced response to working in challenging professional environments or with challenging client cases. It is not solely a phenomenon of health care, but certainly appears in most health care professions, including occupational therapy and student education [7, 19, 22]. Burnout is characterized by Maslach et al. [23] as a presence of emotional exhaustion, depersonalization and cynicism, and a reduced sense of accomplishment in one's work or caregiving roles, which can eventually lead a worker to leave a job or role [5]. Demerouti et al. [15] posit that burnout is a product of the exhaustion and disengagement that result from an imbalance between the interaction of one's job demands and job resources. The World Health Organization lists burnout under problems related to life-management difficulty.

Compassion satisfaction is the positive aspect to professional quality of life. As Stamm [8] states, "it is the pleasure you derive from being able to do your work well ... it is a pleasure to give to others" (p. 12). Many helping professionals report feeling nourished by one's caregiving roles and making contributions toward others as satisfying and are often rejuvenated by such mindsets and experiences. Barton and colleagues [5] offer that role enhancement, the positive aspect of managing multiple roles that procures a sense of health, ego gratification, and enrichment of the personality, may be necessary and helpful for one's satisfaction in work.

There is a dearth of evidence in occupational therapy literature about compassion fatigue or burnout in occupational therapy practitioners, with many sources dating back 30 years, and only a handful in the last decade $[3,4,9,13,22,24]$, with even less in occupational therapy fieldwork educators [5]. Barton and colleagues [5] examined role strain, a different construct - but related to work burnout - in occupational therapy fieldwork educators. Although this study did not examine professional quality of life constructs specifically, the researchers indicated that, compared to nurses and athletic trainers, fieldwork educators exhibited low range overall role strain scores on The Role Strain in Occupational Therapy Fieldwork Educators Inventory (OTFWE Role Strain Inventory), with role overload shown to be a contributing factor to the presence of role strain. Role overload, when one simply does not have enough time to meet requirements of a specific role or roles, may relate to the experience of burnout (as cited in Barton et al. [5]), such as "feeling pressured to cover all aspects of job responsibilities with limited time availability" (p. 321). Workload and time pressures were also reported concerns by Evenson et al. [6] in their survey of fieldwork educators.

Fieldwork education alongside full-time practice is often considered to be a distinct and rewarding opportunity which supports the growth of the profession. The duties as a fieldwork educator also bring stressors and challenges to engagement and personal and job resource management. Understanding the current prevalence of reported burnout, compassion fatigue, and compassion satisfaction in occupational therapy fieldwork educators and the professional factors potentially associated with or which predict professional quality of life is a vital next step in recognizing current experiences in this distinct population and to add to the literature on burnout and role strain [5]. The purposes of this study were to: (1) assess the levels of compassion fatigue, burnout, and compassion satisfaction in occupational therapy fieldwork educators, (2) examine the association of professional characteristics with compassion fatigue, burnout, and compassion satisfaction and 3) reveal the extent to which professional characteristics predict levels of compassion fatigue, burnout, and compassion satisfaction in occupational therapy fieldwork educators. 


\section{Methods}

\subsection{Research design and participant recruitment procedures}

The Institutional Review Board for Human Subjects Review of a university located in the northeastern United States approved this cross-sectional, exploratory study, targeting a convenience sample of occupational therapy fieldwork educators attending a regional occupational therapy education consortium's professional workshop, where data were collected at the end of the workshop. All workshop attendees were eligible to participate in the study and educated about participation and informed consent at the beginning of the workshop in verbal and written formats. Voluntary participation after consent consisted of an attendee anonymously returning the results of a professional quality of life questionnaire and a professional characteristics survey to a designated box at the end of the workshop. Specifically, attendees were instructed to complete the professional quality of life questionnaire in thinking about their role as a fieldwork educator within the last 30 days.

\subsection{Instruments}

Participants completed a professional quality of life questionnaire and a survey that included items about demographic and work characteristics such as age, education level, years in occupational therapy profession, years as a fieldwork educator, number of Level I and Level II fieldwork students per year, total number of students per year, number of identified roles, and practice setting(s). The role question of the survey included a prompt, "check all that apply" for items such as, in addition to fieldwork educator, administrator; student program coordinator, faculty; and other. Participants also completed items to evaluate their response to the continuing education workshop, however, those data were not used for this study and are not reported here.

\subsection{ProQOL}

Compassion fatigue, burnout and compassion satisfaction of participants were assessed using the ProQOL, a 30-item professional quality of life measure [8].

The ProQOL was chosen in part for its solid psychometric properties. Early returns on a test-retest study of the ProQOL suggest good test-retest reliability with a small standard error of the estimate (B.H. Stamm, written communication, October 2012). Three subscales on the ProQOL measure the different constructs, which have demonstrated convergent and discriminant validity using a multitrait, multi-method matrix method of analysis. The three subscales are inter-related, and each subscale describes a different aspect of professional quality of life. Internal consistency reliability of the three, 10-item subscales is excellent: Compassion Satisfaction Cronbach's alpha $\alpha=0.88(n=1180)$; Burnout $\alpha=0.75$ ( $n=976$ ); Compassion Fatigue $\alpha=0.81$ $(n=1135)$ [8]. Participants select their responses with a 5-point Likert scale ranging from 1 (never) to 5 (very often), with directions to think about the last thirty days of their helping role. Each subscale score is measured by the sum of 10 items each, with raw scores converted to $t$ scores. Cut scores are provided at the 25th and 75th percentiles for low and high scores, though the author advises people to use the ProQOL in its continuous form and for screening and longitudinal purposes only, not diagnostic means [8].

\section{Results}

\subsection{Data analysis}

All data were collected and then transferred into a Microsoft Excel file, on a password-protected computer, and stored within Dropbox software, with data analyses performed using Microsoft Excel and IBM SPSS Statistics software (version 23). ProQOL data were uploaded and scored, with reverse scoring for 1 , $4,15,17$, and 29, per scale instructions. Descriptive statistics were used to analyze professional characteristics, while correlational analyses were performed to understand the associations between subscale scores and professional characteristics. These correlations aimed to understand if levels of compassion fatigue, satisfaction, or burnout were predicted by professional characteristic variables in the sample.

\subsection{Professional characteristics}

Of the 153 fieldwork educator workshop attendees, 121 returned study measures (79\% response rate). Four participants' data were not used due to incomplete questionnaires, resulting in a final response number of 117 participants. Table 1 shows the participants' professional characteristics. Most respondents 
Table 1

Professional characteristics

\begin{tabular}{lc}
\hline Variable & $N(\%)$ \\
\hline Professional title & \\
COTA & $20(17.1 \%)$ \\
OTR & $99(84.6 \%)$ \\
Supervisor/Administrator & $33(28.2 \%)$ \\
Student Program Coordinator & $27(23.1 \%)$ \\
Academic: Faculty & $9(7.7 \%)$ \\
Fieldwork Coordinator & $9(7.7 \%)$ \\
Fieldwork Educator & $78(66.7 \%)$ \\
Other & $5(4.2 \%)$ \\
Roles ${ }^{\mathrm{a}}$ & \\
1 & $21(17.8 \%)$ \\
$2-3$ & $83(70.1 \%)$ \\
4 & $11(9.3 \%)$ \\
$5-6$ & $2(1.7 \%)$ \\
Participant's \# of settings ${ }^{\mathrm{b}}$ & \\
1 & $68(58.1 \%)$ \\
2 & $34(29.1 \%)$ \\
$3-4$ & $15(12.8 \%)$ \\
Number of fieldwork students/year ${ }^{\mathrm{c}}$ & \\
0 & $15(12.8 \%)$ \\
$1-3$ & $58(44.1 \%)$ \\
$4-10$ & $38(32.5 \%)$ \\
11 or more & $12(10.3 \%)$ \\
\hline Note. $N$ may not add up to 117 because not all participants answered \\
every question, and/or $n$ may exceed 117 as questions asked for \\
participants to "check all that apply." $n=282 .{ }^{b} n=117 .{ }^{c}=$ Some \\
participants responded with how many students they coordinate or \\
manage, not just supervise, per year, due to question item wording.
\end{tabular}

were women ( $n=112,95.7 \%)$, OTRs $(n=99,84.6 \%)$, inpatient practitioners $(n=50,42.7 \%)$, and identified with having 2 or 3 professional roles $(n=83,70.1 \%)$. The mean age was 42.7 years $(n=93 ; S D=11.5$; range 21 to 69 years). The mean length of years working as a practitioner was 17.1 years $(S D=10.8$; range 1 to 40 years) and mean years working as a fieldwork educator ranged from 1 to 34 years $(M=9.2$; $S D=9.3$ ). Degree levels ranged from associate degree (9.3\%), bachelor's degree (34.7\%), master's degree (51.7\%), to doctorate (4.2\%). In the sample, the average reported number of Level I FW students per year was $2.1(S D=2.6$; range 1 to 12$)$ and average reported number of Level II FW students per year was 1.8 ( $S D=1.5$; range 1 to 6$)$. Reported total number of students educated per year ranged from 1 to 18 students $(M=3.9, S D=3.4)$. The mean number of roles identified was 2.4 roles ( $S D=0.9$; range 1 to 6 roles) and mean number of practice settings was $1.6(S D=0.8)$.

\subsection{Compassion fatigue, burnout, and compassion satisfaction levels}

The ProQOL was used to answer the first research aim to understand participants' reported current levels of compassion fatigue, burnout, and compassion satisfaction. Table 2 shows means, standard deviations, and distribution frequencies for each subscale. The means were similar to the normative sample, and the sample scored in the low to average range for burnout and compassion fatigue, and the average to high range for compassion satisfaction [8]. For compassion fatigue and burnout, a raw score of 22 or less indicates low levels, 23-41 indicates average levels, and 42 and above denotes a high level. For compassion satisfaction, a score of 22 or less suggests low levels, 23-41 indicates average levels and 42 and above denotes a high level. Participants' scores crossed all three levels-low, average and high- for compassion satisfaction, while falling in two levels- low and average- for compassion fatigue and burnout.

Correlations between ProQOL subscales ranged in magnitude, though all were statistically significant $(p<0.01$, two-tailed). Compassion fatigue and burnout were positively correlated with one another $(r=0.56, p<0.01)$ while a large inverse relationship was found between compassion satisfaction and burnout $(r=-0.71, p<0.01)$, and a weak correlation found between compassion fatigue and compassion satisfaction $(r=-0.23, p<0.01)$.

Table 2

Descriptive statistics and distributions for ProQOL subscales

\begin{tabular}{lcccccc}
\hline Scale & Mean $(M)$ & $\begin{array}{c}\text { Standard } \\
\text { deviation }(S D)\end{array}$ & Range & \multicolumn{3}{c}{ Level of ProQOL subscale scores } \\
\cline { 3 - 7 } & & & & $\begin{array}{c}\text { Low } \\
n(\%)\end{array}$ & $\begin{array}{c}\text { Average } \\
n(\%)\end{array}$ & $\begin{array}{c}\text { High } \\
n(\%)\end{array}$ \\
\hline Compassion fatigue (CF) & 100.2 & 15.0 & $68-132$ & $69(58.9 \%)$ & $48(41.0 \%)$ & 0 \\
Burnout (BO) & 100.2 & 14.9 & $73-145$ & $57(48.7 \%)$ & $60(51.3 \%)$ & 0 \\
Compassion satisfaction (CS) & 100.1 & 14.7 & $50-123$ & $1(0.8 \%)$ & $55(47.1 \%)$ & $61(52.1 \%)$ \\
\hline
\end{tabular}

Note. $N=117$. Normative rank of CF, BO, CS- Low $<89$; Average $=90-110 ;$ High $>110$. ProQOL $=$ Professional Quality of Life Scale. ${ }^{a}$ Cut scores provided by Stamm [8]. 
Table 3

Correlational analyses between predictor variables of professional characteristics and ProQOL subscales

\begin{tabular}{lcccccc}
\hline & Age $^{\mathrm{a}}$ & $\begin{array}{c}\text { Number } \\
\text { of roles }\end{array}$ & $\begin{array}{c}\text { Number of FW } \\
\text { students/year }\end{array}$ & $\begin{array}{c}\text { Number } \\
\text { of settings }\end{array}$ & $\begin{array}{c}\text { Years } \\
\text { working }\end{array}$ & $\begin{array}{c}\text { Years as a } \\
\text { FW educator }\end{array}$ \\
\hline Age & 1 & 0.14 & -0.03 & 0.02 & $0.80^{* *}$ & $0.54^{*}$ \\
Number of roles & & 1 & $0.26^{* *}$ & 0.08 & $0.20^{*}$ & $0.27^{* *}$ \\
Number of FW students / year & & & 1 & 0.17 & 0.44 & 0.11 \\
Number of Settings & & & & -0.42 & -0.06 \\
Years working & & & & & 1 & $0.65^{* *}$ \\
Years as FW educator & $0.19^{\dagger}$ & $0.23^{* *}$ & 0.06 & 0.11 & $0.18^{\dagger}$ & $0.20^{\dagger}$ \\
Compassion satisfaction & -0.13 & $-0.17^{\dagger}$ & -0.11 & 0.06 & -0.12 & $-0.18^{\dagger}$ \\
Burnout & -0.06 & -0.13 & -0.06 & -0.03 & -0.04 & -0.02 \\
Compassion fatigue & & & & & & \\
\hline
\end{tabular}

Note. $N=117$ unless otherwise noted. FW = Fieldwork. ProQOL = Professional Quality of Life Scale. ${ }^{a} N=94 .{ }^{*} p<0.05$ level. ${ }^{* *} p<0.01$, two-tailed. ${ }^{\dagger} p<0.10$.

\subsection{Associations between professional characteristics and reported levels of compassion fatigue, burnout, and compassion satisfaction}

Pearson's intercorrelations among professional characteristics and related demographic attributes found that therapists who identified having more professional roles (such as FW educator or student coordinator) also had more years of work in the field $(r=0.20, p<0.05)$; had more years working as a fieldwork educator $(r=0.27, p<0.01)$; and had more fieldwork students per year $(r=0.26, p<0.01)$ (Table 3).

Table 3 also shows the associations between professional characteristics and levels of compassion fatigue, burnout, and compassion satisfaction. Fieldwork educators who reported more compassion satisfaction had a higher number of professional roles $(r=0.23, p<0.01)$, were older $(r=0.19, p=0.07)$, had worked more years in general $(r=0.18, p=0.07)$, and more years specifically as a FW educator $(r=0.17, p=0.07)$ compared to those with less compassion satisfaction. The breakdown of specific role identities (as opposed to number of roles) and type of Fieldwork (Level I and/or II) when analyzed against the subscales did not yield statistically significant results in the correlation. Results of a multiple linear regression analysis reveals the prediction of compassion satisfaction from the combination of the six professional characteristics $\left(\mathrm{R}^{2}=0.15, F=2.46\right.$, $\mathrm{df}_{6,87}, p=0.03$ ) accounted for $15 \%$ of the variance in the compassion satisfaction scores. Burnout had a small negative correlation with the number of roles $(r=-0.17, p<0.10)$ and years as a fieldwork educator $(r=-0.16, p<0.10)$. Professional characteristics were not statistically significant in predicting levels of compassion fatigue or burnout when combined and were thus not entered into the stepwise regression.

Regression analysis for compassion satisfaction indicated that higher compassion satisfaction was predicted for participants' who held more professional roles $(\beta=0.25, p<0.05)$ and had worked greater number of years $(\beta=0.29, p=0.09)$. Table 4

Table 5

Stepwise regression analysis for two predictor variables for compassion satisfaction, excluding all other variables

\begin{tabular}{lccccc}
\hline & $\mathrm{B}$ & $\mathrm{SE}$ & $\beta$ & $t$ & $p$ \\
\hline Number of roles & 4.96 & 1.63 & 0.29 & 3.04 & $0.004^{* *}$ \\
Number of roles+ & 4.26 & 1.62 & 0.26 & 2.63 & $0.010^{\text {** }}$ \\
years working & 0.30 & 0.129 & 0.24 & 2.28 & $0.025^{*}$ \\
\hline
\end{tabular}

${ }^{*} p<0.05 .{ }^{* *} p<0.01$.

Table 4

Summary of stepwise regression analysis for two predictors for compassion satisfaction

\begin{tabular}{|c|c|c|c|c|c|c|c|c|}
\hline Predictor variable & & $\mathrm{df}$ & $\begin{array}{l}\text { Sum of } \\
\text { squares }\end{array}$ & $\begin{array}{l}\text { Mean } \\
\text { square }\end{array}$ & $\mathrm{F}$ & $p$ & $R$ & $R^{2}$ \\
\hline \multirow{3}{*}{ Number of roles } & Regression & 1 & 1787.97 & 1787.97 & 9.26 & $0.003^{*}$ & 0.30 & 0.09 \\
\hline & Residual & 92 & 17773.99 & 193.20 & & & & \\
\hline & Total & 93 & 19561.96 & & & & & \\
\hline \multirow{3}{*}{$\begin{array}{c}\text { Number of roles }+ \\
\text { years working }\end{array}$} & Regression & 2 & 2749.04 & 1374.52 & 7.44 & $0.001^{*}$ & 0.38 & 0.14 \\
\hline & Residual & 91 & 16812.92 & 184.76 & & & & \\
\hline & Total & 93 & 19561.96 & & & & & \\
\hline
\end{tabular}

Note. Compassion satisfaction is the dependent variable. ${ }^{*} p<0.01$. 
shows stepwise regression results in which the first variable entered into the prediction of compassion satisfaction was number of roles $(\beta=0.29, t(116)$ $=3.04, p=0.004$ ), accounting for $9.0 \%$ of the variance. The second variable entered into the prediction was the amount of years working, accounting for an additional $5.0 \%$ of the variance in compassion satisfaction scores $(\beta=0.24, t(116)=2.28, p=0.025)$ (Table 5).

\section{Discussion}

The findings of this study revealed high levels of compassion satisfaction and low to average levels of compassion fatigue and burnout in occupational therapy fieldwork educators attending a fieldwork education workshop. To these researchers' knowledge, there are no comparable studies of occupational therapy fieldwork educators and specific findings from the ProQOL subscales. There is another study of fieldwork educators that examined role strain [5], but most other studies in the literature explored burnout and compassion fatigue in the general occupational therapy population and / or groups of practitioners, such as those working in mental health. Results of the sample's ProQOL subscale frequencies from this study thus are compared to other studies of reported ProQOL subscale levels in practitioners in the health professions, who may or may not have specified practice educator roles, due to the perceived dearth of literature in examining compassion fatigue, burnout, and compassion satisfaction in health practitioners who identify as educators.

This study's findings are consistent with the literature surveying mostly homogenous helping professionals in general, including one recently published about occupational therapy practitioners (not specifically fieldwork educators) [3], emergency department nurses [25], and US healthcare workers [26]. These studies all had samples with high levels of compassion satisfaction and low to average levels of burnout and compassion fatigue, but were not specific to practice educators. Scanlan \& Still [9] similarly found that occupational therapy practitioners working in mental health reported low exhaustion and work disengagement levels, indicators of burnout, via the Oldenberg Burnout Inventory (OBLI). Occupational therapy practitioners from this study who reported intention to stay at their job and reported satisfaction at work identified a supportive work environment, or job resources, as outlined by Demerouti et al. [15], and interesting and challenging work, while those who reported possible turnover indicated low managerial support, high workplace expectations, and a feeling of helplessness with clients as indicators of dissatisfaction. As did this study, Scanlan and Still [9] similarly queried their sample about professional work characteristics yet highlighted very different but important factors at work that influence one's perception of work satisfaction or burnout and did not focus on the fieldwork educator role.

In contrast to the above findings of low burnout in practitioners, not identifying as fieldwork educators, previous studies about fieldwork educators revealed that those in a dual role of therapist-educator appear to be more prone to feelings that may adversely relate to professional quality of life. Such studies closely examined more distinct aspects of the fieldwork educator role as compared this the current study $[5,6]$. Role strain, role overload, a lack of identity or role ambiguity, reduced connection to peers, workload pressures and time constraints, and a sense of incongruence are some of the lived experiences reported by fieldwork educators [5, 6, 16, 17, 27]. In prior research, occupational therapy practitioners, not identified as fieldwork educators, who took the Maslach Burnout Inventory (MBI) or MBI-Human Service Survey (MBI-HSS), scored in the moderate range in both a Canadian study [13] and a Filipino study [28]. A similar study examining occupational therapist burnout and work engagement in Australia, using the OLBI, also reported mild-range burnout [4]. Our contrasting finding of low burnout levels may have been a result of the ProQOL assessing both positive and negative attributes of work. Or, perhaps, our sample, with an average of having 2.4 roles; working 17.1 years; average age of 42.7; and average of working as a fieldwork educator as 9.2 years have had experiences and opportunities within their work to express different or broader skills in more or varied roles, as compared to occupational therapy practitioners involved in the Gupta [13] and Delos Reyes [28] studies. As one ages, and thus works longer in the field, opportunities to take on assorted roles and educate students, and learn and apply evidence-based practices also increase. Conceivably, the extra roles bring with them a source of nourishment and engagement, and perhaps novel identity, a contrast from direct client care. Adapting one's work by altering job demands may feed a sense of renewal or rejuvenation in daily or life-long work-related quality of life. Crafting one's balance between personal resources, job resources and job demands may also detract from 
role overload and role strain and result instead in role enhancement $[5,29]$. Fieldwork educators with the highest level of compassion satisfaction in this study appear to be functioning in more roles, at an engaged and expert (experienced) level. This is characterized by a sense of mastery, after years of navigating the job demands of practice and fieldwork supervision education by utilizing available work and personal resources to foster engagement, manage roles and experience greater inherent work satisfaction.

The study results also indicate that younger or near entry-level fieldwork educators may experience less compassion satisfaction than older or more experienced fieldwork educators. Extra roles and work duties are often not a priority or opportunity for younger or entry-level therapists, as they transition from graduate, through the "angst and euphoria" and "reality of practice" phases to finally, after the first year, the "adaptation stage" [30]. Early in an occupational therapist's career, more time is spent on self-evaluation of clinical reasoning skills, application of foundational knowledge, and overall management of job demands, to demonstrate job and role competence. Experienced fieldwork educators and practitioners are beckoned to not only support the transition to practice and ease the shock factor, but to also provide opportunities early on in a newer practitioner's career to embrace new or differing roles, in an environment supportive of professional identity building and resource management, and breadth of learning [5, 31]. Such mentorship will provide avenues for new practitioners to see beyond the scope of direct client care and organizational job demands as a sole path to finding one's career as satisfying and rewarding and may enhance present-moment engagement in client and fieldwork student relationships.

This study revealed specific professional characteristics which correlate with reported levels of compassion satisfaction in a small convenience sample of fieldwork educators when asked to think about their work. In this small sample of fieldwork educators, a predictive work attribute of compassion satisfaction was the reported number of professional roles, with years working added to round out $15 \%$ of the variance. The findings are consistent with previous research in the occupational therapy literature indicating that a diversified workload, such as exercising roles of occupational therapy practitioner and fieldwork educator, along with increased age and years working, may reduce burnout, lessen role strain, and support one in feeling more content with one's work $[5,13,32]$.

\subsection{Limitations}

This study had several limitations. The cross-sectional design of the research was a significant limitation. Had the sample been surveyed longitudinally over many instances, instead of during a one-time data gathering event, results may have shown the impact of professional characteristics over time on reported levels of compassion fatigue, burnout, and compassion satisfaction, or possibly how any changes in the levels may have been impacted by varying roles or number of students or other work factors. Another potential limitation of this study was the use of a standardized assessment of professional quality of life. The ProQOL is designed for any helping professional to think upon their last 30 days in their role while completing the form [8], and despite instructing the participants to think upon their fieldwork educator role specifically, the researchers could not control for how the study participants interpreted this prompt or the prompts on the ProQOL form itself. Results may thus have been impacted if the participant was thinking about their practitioner role(s) and duties and not specifically their fieldwork educator role. As well, open-ended questions may have elicited a greater range of responses regarding other variables that may impact reported professional quality of life instead of on the ProQOL or use of other measures examining burnout may have highlighted the nuances of burnout versus compassion fatigue. In addition to the limiting use of the ProQOL, the professional characteristics collected may not have fully captured specific factors to the fieldwork educator role that may have brought more certainty to the results and implications for fieldwork educators. Though years as a Fieldwork educator, number of Level I \& II FW students per year and total per year were gathered, other characteristics of the general practitioner role were also collected, such as roles in addition to educator and number of settings. It is possible that the fieldwork educators mixed their identify of occupational therapy practitioner with fieldwork educator when completing the form.

Another limitation of the study is that the sample population was recruited from a convenience sample of those attending an in-person, free, one-time regional workshop who were specifically fieldwork educators and pursuing continuing education for this role, specifically, at the workshop. Attending the workshop may also have been championed by the study participants' work organizations, possibly indicating that the attendees may be those who feel 
supported in their workplace and in the fieldwork educator role, specifically, making the results less generalizable to the rest of the fieldwork educator population. Consequently, the sample was also not randomized, and did not have as far a reach as an electronic survey may have, had the study been delivered to listservs of fieldwork educators across the nation, and possibly across borders to international colleagues involved in practice education. Thus, findings may not translate to or represent more diverse populations of occupational therapy practitioners and certified occupational therapy assistants who participate in fieldwork or practice education, or to those who experience other job roles and work characteristics and demands of a different nature.

\subsection{Directions for future research}

While these preliminary results may suggest that a higher number of roles might produce a happier and more satisfied workforce of fieldwork educators, much more research is required to understand what contributes to professional quality of life in fieldwork educators, across a much larger and representative pool, and over time. It might be that the reverse is true. Those individuals who are satisfied in general with working as an occupational therapy practitioner, or who find success or perceived health in balancing job demands and job resources, may take on more roles, such as fieldwork educator or student clinical coordinator. More specific professional details regarding the distinct nature and job demands of the fieldwork educator role should be gathered to delineate from "practitioner" and "fieldwork educator." Future important research to expand on this preliminary work and enrich the fieldwork educator literature surrounding burnout, compassion fatigue and compassion satisfaction may be to use the tool adapted and developed by Barton and colleagues [5], the Role Strain in Occupational Therapy Fieldwork Educators Inventory (OTFWE Role Strain Inventory). Combining this tool, which asks distinct questions specific to the OT fieldwork educator role with the ProQOL or another burnout measure together and polling fieldwork educators across the nation, as Barton et al. did, may reveal more salient fieldwork educator issues and those that predict levels of compassion fatigue, burnout, and compassion satisfaction. Larger studies, particularly with longitudinal designs, are needed to examine other predictive factors of fieldwork educators' professional quality of life not examined in this research and how such factors change over time, with careful study design of the survey tools, methods, and deeper statistical analyses. For instance, the practice environments' acuity may impact the fieldwork educator experience of job demands and personal resource management, and productivity expectations specific to an organization or system may predict a fieldwork educator's level of burnout, compassion satisfaction or fatigue.

The professional characteristics examined in this study accounted for only $15 \%$ of the variance in compassion satisfaction, leaving $85 \%$ of the variance unaccounted, which is significant. Many other influential factors, such as level of practitioner training for Level I and II Fieldwork supervision, mandated or personal choice in taking student, personal coping strategies, external social supports, personality, socioeconomic status, managerial support, current productivity demands, and organizational or personal resources for advancement, which were not collected in this research, may have affected the reported scores on the ProQOL subscales. It would be beneficial to examine a random sample of fieldwork educators across the nation or across borders, or to study this same group at different points in time in their careers which many more details specific to the educator role to further detect predictors of compassion satisfaction and potential predictors of burnout and compassion fatigue. Furthermore, the national survey of fieldwork educators by Evenson et al. [6] found that over $80 \%$ of OTRs supervise occupational therapy assistant (OTA) students, and so our sample, with $84.6 \%$ as OTRs, was representative of current supervision and role expression trends of fieldwork educators. However, future replication of this study examining professional characteristics of OTA fieldwork educators, while supervising OTA students, specifically, is warranted. Finally, Level I and Level II fieldwork placements require different types of student supervision, at varying degrees of time commitment and, often, preparation and training. Future research should include more detailed demographic information about the participants' Fieldwork supervision, such as gathering numbers by type (Level I or II), role preparation and educators' attitudes, with more indepth analyses of these factors to capture their impact on compassion satisfaction, burnout, and compassion fatigue in this specific population of fieldwork educators.

Younger and novice fieldwork educators in this study reported less compassion satisfaction than their older and/or more experienced peers. Research directed at understanding the needs of therapy 
practitioners new to the role of fieldwork educator would contribute to the development of trainings and guidelines for supportive work environments in which fieldwork educators practice, which may decrease burnout and compassion fatigue, role strain, possible workplace fatigue, and may enhance work satisfaction [2, 5]. Morley [33] found that the transition from academia to novice occupational therapist comes with a shift to limited peer contact and increasing autonomy. A more positive experience was found when supervisors of entry-level therapists acted to ease the transitions, such as clarifying job duties, policies, and overall support during the entry [33]. Novice and young fieldwork educators also would benefit from mentors, such as student program coordinators, to support the transition into the distinct challenges of supervising students.

\section{Conclusion}

This research contributes to preliminary understanding of the reported levels of compassion fatigue, burnout, and compassion satisfaction in a small sample of occupational therapy practitioners who identify as fieldwork educators, as related to engaging in multiple professional roles. It was found in this sample of fieldwork educators that engaging in more roles in one's professional work and greater years of work experience predicted higher compassion satisfaction. Younger, novice practitioners who are fieldwork educators appeared to be less satisfied professionally. Implications for practice include examining the distinct work characteristics of the fieldwork educator role more in-depth that may affect work satisfaction, and exploring the feasibility of a more rigorous, consistent approach to offering supportive transitions from didactic and fieldwork graduate education to practice and student supervision roles for novices, while building awareness of personal and professional resources to combat the challenges of fieldwork education.

Given the higher compassion satisfaction levels reported by more experienced fieldwork educators in this study, ideally, a pipeline of mentorship provided by these clinicians may validate the lived experiences of perceived compassion fatigue, burnout, and compassion satisfaction in entry-level or less experienced fieldwork educators. Employers or supervisors of fieldwork educators may want to organize a mentoring program between "old and young" educators or encourage more experienced fieldwork educators to offer their wisdom on deriving satisfaction from work and the job duties when onboarding new practitioners to the educator role. The American Occupational Therapy Organization (AOTA) also provides many resources regarding mentorship, and the profession advocates for mentoring relationships that support growth between all levels of practitioners [34].

Furthermore, work institutions can also provide early opportunities for novice practitioners to value the importance of expanding skill sets to other job roles in one's professional life, apart from practitioner, by offering student supervision roles as soon as accreditation and practice guidelines allow [15, 29]. Such support from the employer organization may foster work satisfaction and role enhancement and assist novices and young fieldwork educators in feeling energized and engaged in an assortment of roles, especially while educating a student and managing a client caseload, productivity expectations, and variables of the practice environment. Additionally, work settings may also sponsor participation in the Fieldwork Educator Certificate Program, offered by AOTA, multiple times a year both regionally and at the annual conference, to support skill development in instructional practices and navigating student supervision [35]. Systems and organizations may benefit from conducting regular needs assessments regarding reported professional quality of life and gather identified sources of possible compassion fatigue, burnout, or role strain to highlight the distinct and changing job demands that challenge their staff in providing quality care and quality student fieldwork education, over time. Organizations and managers can gauge how fieldwork educators perceive productivity expectations or high stress practice environments, often understood to raise ethical conflicts and increase stress, tension and job demands [36], while detracting from personal resources, amidst times of student supervision, especially, and seek to understand how more experienced educators versus less experienced educators navigate these challenges. Considering the coronavirus disease 2019 (COVID-19) pandemic, job demands have risen, with many experienced fieldwork educators opting to retire or work less, leading to disruption in possible mentors, as well as in all roles and personal and professional resources among occupational therapy practitioners and fieldwork educators [37, 38]. Fieldwork education during the pandemic includes modeling to and coaching the student in many new practice tasks; adherence to new and changing safety protocols; creatively including family and caregivers in interventions and family 
education; and integrating telehealth and other innovative technologies to support delivery of care to patients, on top of the other characteristics [39]. Such added dimensions to the fieldwork education experience in the context of COVID-19 are bound to increase anxiety and distress surrounding personal life management and stretched job duties, which may contribute to acute or longer-term burnout, compassion fatigue, ethical anguish, or decreased job satisfaction in young and novice fieldwork educators, as well as those with more experience and more roles. Additionally, with the documented increase in student programs and enrollment, and shortage of qualified fieldwork educators in the field to supervise students and mentor younger or less experienced fieldwork educators [40], it is important to note that during a pandemic or in practice environments that have high productivity expectations or high stress, that the needs of novice and expert practitioners, as student supervisors, may have shifted and require different or more support for successful participation in job roles and to enhance professional quality of life. With ongoing needs assessments, workplace systems could respond with programming to support workplace wellness and highlight professional resources available to staff to support professional quality of life and role management in the fieldwork educator role and those with multiple roles. Such variables that either change or are constant in need of assessment include, though not examined directly in this study, consideration of the COVID-19 pandemic, settings or times when less experienced educators are asked to take on students with minimal mentorship or guidance, the attitudes of the fieldwork educators toward student education, or with administrative expectations for high productivity governing much of client care procedures [36, 41]. The ProQOL or another psychometrically sound measure could be used to measure the effects of resultant programs on professional quality of life factors over time. Student and client outcomes and satisfaction levels could also be evaluated in future, and broad and longitudinal studies conducted to understand the relationship of fieldwork educator reported quality of life factors on perceived quality of care and education. This study suggests that much more research is needed to understand what factors distinct to the role of fieldwork educators contribute to an occupational therapy work force of fieldwork educators, young and old, that is prepared to navigate the requirements for treating diverse populations of clients while educating students with diverse needs and navigating additional workplace roles and responsibilities.

\section{Acknowledgments}

The authors would like to acknowledge Margaret L. Morris, OTD, OTR/L, BCP of Tufts University and Kimberly Ames, OTD, for their contributions to the development of this manuscript.

\section{Conflict of interest}

The authors have no known conflicts of interest to disclose.

\section{References}

[1] Association AOT. 2018 Accreditation Council for Occupational Therapy Education (ACOTE®) standards and interpretive guide (effective July 31, 2020). Am J Occup Ther [Internet]. 2018 [cited 2020 May 21;72 Suppl 2:7212410005p1-7212410005p83. Available from: https://ajot.aota.org/article.aspx?articleid=2716477 doi: 10 . 5014/ajot.2018.72S217

[2] Brown CA, Schell J, Pashniak LM. Occupational therapists' experience of workplace fatigue: Issues and action. Work [Internet]. 2017 [cited 2020 May 24 ];57(4):517527. Available from: https://content.iospress.com/articles/ work/wor2576 doi: 10.3233/WOR-172576

[3] Chen CC. Professional quality of life among occupational therapy practitioners: An exploratory study of compassion fatigue. Occup Ther Ment Health [Internet]. 2020 [cited $2020 \mathrm{Jul} \mathrm{01}$ ];36(2):162-75. Available from: https://www.tandfonline.com/doi/full/10.1080/0164212X. 2020.1725713 doi: 0.1080/0164212X.2020.1725713

[4] Poulsen AA, Meredith P, Khan A, Henderson J, Castrisos V, Khan SR. Burnout and work engagement in occupational therapists. Br J Occup Ther [Internet]. 2014 [cited $2020 \mathrm{Jul}$ 14];77(3):156-64. Available from: https://journals.sagepub. com/doi/10.4276/030802214X13941036266621

[5] Barton R, Corban A, Herrli-Warner L, McClain E, Riehle D, Tinner E. Role strain in occupational therapy fieldwork educators. Work [Internet]. 2013 [cited $2021 \mathrm{Feb} 28$ ];44(3):317-28. Available from: https://content. iospress.com/articles/work/wor01508 doi: 10.3233/WOR121508

[6] Evenson ME, Roberts M, Kaldenberg J, Barnes MA, Ozelie R. National survey of fieldwork educators: Imp lications for occupational therapy education. Am J Occup Ther [Internet]. 2015 [cited 2020 May 21];69 Suppl 2:6912350020p1-6912350020p5. Available from: https:// ajot.aota.org/article.aspx?articleid=2464349 doi:10.5014/ ajot.2015.019265

[7] Luken M, Sammons A. Systematic review of mindfulness practice for reducing job burnout. Am J Occup Ther [Internet]. 2016 [cited $2020 \mathrm{Jul}$ 01];70(2):7002250020p17002250020p10. Available from: https://ajot.aota.org/ article.aspx ?articleid=2484239 doi:10.5014/ajot.2016.01 6956

[8] Stamm BH. The concise ProQOL manuscript [Internet]. Pocatello, ID: Proqol.org 2020 [cited 13 July 2020]. Available from: https://proqol.org/uploads/ProQOLManual.pdf 
[9] Scanlan JM, Still M. Job satisfaction, burnout and turnover intention in occupational therapists working in mental health. Aust Occup Ther J [Internet]. 2013 [cited 2020 Jul 11]; 60(5):310-18. Available from: https://online library.wiley.com/doi/abs/10.1111/1440-1630.12067 doi: 10.1111/1440-1630.12067

[10] Joinson C. Coping with compassion fatigue. Nurs [Internet]. 1992 [cited 2020 Jul 01];22(4):116-21. Available from: https://journals.lww.com/nursing/Citation/1992/04000/CO PING_WITH_COMPASSION_FATIGUE.35.aspx doi: 10. 1097/00152193-199204000-00035

[11] Maslach C, Leiter MP, Schaufeli W. Measuring burnout. In Cooper, CL \& Cartwright, S, eds. The Oxford handbook of organizational well-being. Oxford UK: Oxford University Press; 2009;86-108.

[12] Rodger S, Thomas Y, Greber C, Broadbridge J, Edwards A, Newton J, et al. Attributes of excellence in practice educators: The perspectives of Australian occupational therapy students. Aust Occup Ther J [Internet]. 2013[cited 2020 Jun 28];61(3):159-67. Available from: https://onlinelibrary. wiley.com/doi/abs/10.1111/1440-1630.12096 doi: 10.11 11/1440-1630.12096

[13] Gupta S, Paterson ML, Lysaght RM, von Zweck CM. Experiences of burnout and coping strategies utilized by occupational therapists. Can J Occup Ther [Internet]. 2012 [cited 2020 Jul 13];79(2):86-95. Available from: https:// journals.sagepub.com/doi/10.2182/cjot.2012.79.2.4 doi:10. 2182/cjot.2012.79.2.4

[14] Reid D. Capturing presence moments: The art of mindful practice in occupational therapy. Can J Occup Ther [Internet]. 2009 [cited 2020 May 28];76(3):180-188.Available from: https://journals.sagepub.com/doi/10.1177/00084174 0907600307 doi: $10.1177 / 000841740907600307$

[15] Demerouti E, Bakker AB, Nachreiner F, Schaufeli WB. The job demands-resources model of burnout. J App Psychol [Internet]. 2001 [cited 2020 Jul 14];86(3):499-512. Available from: https://psycnet.apa.org/doiLanding?doi= 10.1037\%2F0021-9010.86.3.499 doi: 10.1037/0021-9010. 86.3.499

[16] Higgs J, McAllister L. The lived experiences of clinical educators with implications for their preparation, support and professional development. Learn Health Soc Care [Internet]. 2005 [cited $2020 \mathrm{Jul} 11$ ];4(3):156-71. Available from: https://onlinelibrary.wiley.com/doi/abs/10.1111/j.1473-68 61.2005.00097.x doi: 10.1111/j.1473-6861.2005.00097.x

[17] Stutz-Tanenbaum P, Hooper B. Creating congruence between identities as a fieldwork educator and practitioner. Educ Special Interest Section Quarterly [Internet]. 2009 [cited 2020 May 21];19(2):1-4. Available from:

[18] Zeman E, Harvison N. Burnout, stress, and compassion fatigue in occupational therapy practice and education: A call for mindful, self-care protocols. NAM Perspectives [Internet]. 2017 [cited 2020 Jul 01];7(3). Available from: https://nam.edu/burnout-stress-and-compassion-fatigue-inoccupational-therapy-practice-and-education-a-call-for-mi ndful-self-care-protocols/ doi: 10.31478/201703g

[19] Yuen HK. Fieldwork students under stress. Am J Occup Ther [Internet]. 1990 [cited 2020 Jul 13];44(1):8081. Available from: https://ajot.aota.org/article.aspx?arti cleid=1876897 doi: 10.5014/ajot.44.1.80

[20] Mackenzie L, Zakrzewski L, Walker C, McCluskey A. Meeting the educational needs of fieldwork supervisors: A collaborative workshop developed by New South Wales occupational therapy fieldwork coordinators. Aust Occup Ther J [Internet]. 2008 [cited 2020
Jul 11];48(1):1-10. Available from: https://onlinelibrary. wiley.com/doi/abs/10.1111/j.1440-1630.2001.00233.x doi: 10.1111/j.1440-1630.2001.00233.x

[21] Sorenson C, Bolick B, Wright K, Hamilton R. Understanding compassion fatigue in healthcare providers: A review of current literature. J Nurs Scholarsh [Internet]. 2016 [cited 2020 Jul 13];48(5):456-65. Available from: https://sigmapubs.onlinelibrary.wiley.com/doi/abs/10.1111/ jnu.12229 doi: 10.1111/jnu.12229

[22] Brollier C, Bender D, Cyranowski J, Velletri CM. A pilot study of job burnout among hospital-based occupational therapists. Occup Ther J Res [Internet]. 1986 [cited 2020 Jun 28];6(5):285-99. Available from: https:// journals.sagepub.com/doi/10.1177/153944928600600503 doi:10.1177/153944928600600503

[23] Maslach C, Jackson S, Leiter M. Maslach burnout inventory.. In Zaloquett C, Wood R, eds. Evaluating stress: A book of resources.. Lanham, Md. \& London: The Scarecrow Press, Inc; 1997;191-218.

[24] Leland NE, Armstrong M. Compassion fatigue: A scoping review of the literature. Am J Occup Ther [Internet]. 2015 [cited 2020 Jul 13];69 Suppl. 1:247-50. Available from: https://ajot-aota-org.treadwell.idm.oclc.org/article. aspx ?articleid=2491001 doi: $10.5014 /$ ajot.2015.69S1-RP 207C

[25] Hunsaker S, Chen HC, Maughan D, Heaston S. Factors that influence the development of compassion fatigue, burnout, and compassion satisfaction in emergency department nurses. J Nurs Scholarsh [Internet]. 2015 [cited 2020 May 28];47(2):186-94. Available from: https://sigmapubs. onlinelibrary.wiley.com/doi/abs/10.1111/jnu.12122 doi: 10.1111/jnu. 12122

[26] Smart D, English A, James J, Wilson M, Daratha KB, Childers B, et al. Compassion fatigue and satisfaction: A cross-sectional survey among US healthcare workers. Nurs Health Sci [Internet]. 2013 [cited 2020 Jul 01];16(1):3-10. Available from: https://onlinelibrary.wiley. com/doi/abs/10.1111/nhs. 12068 doi: 10.1111/nhs. 12068

[27] Roberts M, Evenson E, Barnes MA, Kaldenberg J, Ozelie R. Fieldwork education survey: Demand for innovative and creative solutions. OT Pract [Internet]. 2015 [Cited 2021 Feb 26];20(9):15-6. Available from: https://www.aota.org/-/ media/Corporate/Files/Secure/Publications/OTP/2015/OTPvolume-20-Issue-9.pdf

[28] Delos Reyes RC. Burnout among Filipino occupational therapists: A mixed methods analysis. Open J Occup Ther [Internet]. 2018 [Cited 2020 Jul 01];6(4): 1-13. Available from: https://scholarworks.wmich.edu/ojot/vol6/iss4/7/ doi: 10.15453/2168-6408.1469

[29] Bakker A, Hakanen J, Demerouti E, Xanthopoulou D. Job resources boost work engagement, particularly when job demands are high. J Educ Psychol [Internet]. 2007 [Cited on 2020 Jul 13];99(2):274-84. Available from: https://doi.apa.org/doiLanding?doi=10.1037\%2F00220663.99.2.274 doi:10.1037/0022-0663.99.2.274

[30] Tryssenaar J, Perkins J. From student to therapist: Exploring the first year of practice. Am J Occup Ther [Internet]. 2001[cited 2020 Jul 13];55(1):19-27. Available from: https://ajot.aota.org/article.aspx?articleid=1868948 doi: 10.5014/ajot.55.1.19

[31] Morley M. Moving from student to new practitioner: The transitional experience. Br J Occup Ther [Internet]. 2006 [Cited $2020 \mathrm{Jul}$ 01];69(5):231-233. Available from: https://journals.sagepub.com/doi/10.1177/0308022606069 00506 doi: 10.1177/030802260606900506 
[32] Lloyd C, King R. Work-related stress and occupational therapy. Occup Ther Int [Internet]. 2001 [Cited 2020 Jul 14];8(4):227-43. Available from: https://onlinelibrary. wiley.com/doi/abs/10.1002/oti.148 doi: 10.1002/oti.148

[33] Morley M. Contextual factors that have an impact on the transitional experience of newly qualified occupational therapists. Br J Occup Ther [Internet]. 2009 [cited 2020 Jul 14];72(11):507-14. Available from: https://journals. sagepub.com/doi/10.4276/030802209X12577616538753 doi: $10.4276 / 030802209 X 12577616538753$

[34] Waite A. Guiding forces: Finding and benefiting from occupational therapy mentors. OT Pract. [Internet]. 2014. [Cited 2021 Feb 26]19(17):7-10. Available from: https:// www.aota.org/-/media/Corporate/Files/Secure/Publicatio ns/OTP/2014/OTP\%20Vol\%2019\%20Issue\%2017.pdf

[35] Association AOT. Fieldwork educator certificate program [Internet]. 2020 [updated 2020, cited 2019 September 24]. Available from: https://www.aota.org/Education-Care ers/Fieldwork/Workshop.aspx

[36] Winistorfer W, Scheirton L, Slater DY. Ethical considerations for productivity, billing, and reimbursement. OT Pract. [Internet]. 2017. [Cited 2021 Feb 27];22(22):13-8. Available from https://www.aota.org/-/media/Corporate/Fi les/Secure/Publications/OTP/2017/OTP-Volume-22-Issue22-Buyers-Guide.pdf

[37] Shanafelt T, Ripp J, Trockel, M. Understanding and addressing sources of anxiety among health care professional during the COVID-19 pandemic. JAMA [Internet].
2020 [cited 2020 Jul 13]0;323(21):2133-4. Available from: https://jamanetwork.com/journals/jama/fullarticle/2764380 doi: 10.1001/jama.2020.5893

[38] Association AOT. An ethical response to the COVID-19 pandemic: An AOTA ethics advisory opinion [Internet]. 2020 [updated 2020, cited 2020 July 20]. Available from: https://www.aota.org//media/Corporate/Files/Practice/Eth ics/Advisory/Ethical-Response-to-COVID-19.pdf.

[39] del Pozo E, Herman A. Strategies for managing burnout: Fostering more self-awareness, setting clear objectives and more. OT Pract. [Internet]. 2020. [Cited $2021 \mathrm{Feb}$ 27];25(12):24-6. Available from: https://www.aota.org/-/ media/Corporate/Files/Secure/Publications/OTP/2020/OT P-Volume-25-Issue-12-December-2020-Buyers-Guide.pdf

[40] Harvison N. AOTA current trends in accreditation and higher education. [Internet]. 2018. [Cited $2021 \mathrm{Feb} 28$ ]. Available from: https://www.aota.org/ /media/Corporate/ Files/EducationCareers/2018-conference-presentations/ 2018-Trends-in-Accreditation-Higher-Education.

[41] Association AOT. Practitioner well-being decision guide to address anxiety and acute stress [Internet]. 2020 [updated 2020, cited 2020 July 21]. Available from: https:// www.aota.org//media/Corporate/Files/Practice/Health/Addr essing-Acute-Stress-Anxiety.pdf. 